Article

\title{
High-Loaded Bioflocculation Membrane Reactor of Novel Structure for Organic Matter Recovery from Sewage: Effect of Dissolved Oxygen on Bioflocculation and Membrane Fouling
}

\author{
Liguo Wan ${ }^{1,2,3, *}$, Ling Xiong ${ }^{2}$, Lijun Zhang ${ }^{2}$ and Wenxi Lu ${ }^{1, *}$ \\ College of New Energy and Environment, Jilin University, Changchun 130021, China \\ 2 School of Water Conservancy \& Environment Engineering, Changchun Institute of Technology, \\ Changchun 130012, China; xiongling@ccit.edu.cn (L.X.); zhanglijun@ccit.edu.cn (L.Z.) \\ 3 Jilin Provincial Key Laboratory of Municipal Wastewater Treatment, Changchun Institute of Technology, \\ Changchun 130012, China \\ * Correspondence: wanliguo@ccit.edu.cn (L.W.); luwenxi@jlu.edu.cn (W.L.); Tel.: +86-138-9488-6881
}

Received: 7 August 2020; Accepted: 5 September 2020; Published: 9 September 2020

\begin{abstract}
In this study, a new structure of high-load membrane bioreactor (HLB-MR) was used to treat urban sewage, and the effects of dissolved oxygen (DO) on biological flocculation and membrane pollution were researched. Parallel comparative experiments were used to investigate the concentration and recovery efficiency of organic matter, the bioflocculation effect, the content of extracellular polymer substance (EPS), the concentration of metal cations, membrane fouling status and microbial community structure in the reactors under the conditions of $1-2$ and $6-8 \mathrm{mg} / \mathrm{L}$. The flocculation efficiency of HLB-MR was $83 \%$ and $89 \%$ when DO was $1-2$ and $6-8 \mathrm{mg} / \mathrm{L}$, respectively. Under DO of $6-8 \mathrm{mg} / \mathrm{L}$, the contents of bound and free EPS in the HLB-MR were $15.64 \mathrm{mg} / \mathrm{gVSS}$ and $8.71 \mathrm{mg} / \mathrm{L}$, respectively. These values were significantly higher than those obtained when DO was $1-2 \mathrm{mg} / \mathrm{L}(11.83 \mathrm{mg} / \mathrm{gVSS}$ and $6.56 \mathrm{mg} / \mathrm{L}$, respectively). Moreover, the concentrations of magnesium and aluminum in the concentrate of the HLB-MR were significantly higher when DO was 6-8 mg/L. Under higher DO concentration, there would be more EPS combined with metal cations, and thus fixed in the sludge substrate, the process of which promoted the bioflocculation. Changes in the transmembrane pressure (TMP) showed that the HLB-MR at a higher DO concentration suffered more serious membrane fouling. The species difference between the supernatant and precipitate was more significant under a higher DO concentration. The plankton species in the supernatant, e.g., norank_p_Saccharibacteria, norank $f \_$Neisseriaceae, and 12up, were likely to exacerbate membrane fouling. However, the species in the precipitate like Trichococcus, Ornithinibacter, and norank $f \_$Saprospiraceae may have a positive effect on bioflocculation.
\end{abstract}

Keywords: membrane reactor; bioflocculation; municipal wastewater; dissolved oxygen; organic matter

\section{Introduction}

With the increasing shortage of global resources, urban sewage should no longer be only considered as an object of "waste treatment"; rather, it should be considered a carrier of ample "resources and energy". At present, increasing attention is concentrated on achieving a "carbon neutral" operation for urban sewage treatment plants. Several methods widely report the recycling and utilization of resources of carbon (organic matter) in urban sewage [1-3]. As the suspended organic matter (SOM) and the colloidal organic matter (COM) together account for more than $70 \%$ of the total organic matter, many researchers prefer membrane separation as the method for concentrating organic matter in the wastewater. However, when the raw urban sewage water is 
filtered in an untreated manner, problems like serious membrane fouling and a sharp decline in the membrane flux arise [4,5]. Pretreatment of coagulation helps in removing particles and colloids from the sewage and thus effectively mitigates membrane fouling [6-9]. However, drawbacks such as high cost, secondary fouling and possibly inhibited anaerobic energy production of organic matters also arise when the coagulant is added. In bioflocculation, microorganisms or the extracellular polymeric substance (EPS) secreted by them are utilized to collect colloids and particulate matter from the sewage [10]. Compared with coagulation, bioflocculation is more aligned with the requirements of sustainable development and has the advantage of lower cost and no secondary fouling. This study describes the development of high-loaded bioflocculation membrane reactor (HLB-MR) by controlling the extremely short hydraulic retention time (HRT) and the solids' retention time (SRT). The idea behind this was to flocculate the SOM and COM in the wastewater by utilizing the EPS produced by the microorganisms. This would mitigate fouling in the membrane separation and concentrate and recover the organic matter present in the wastewater for subsequent anaerobic energy production.

Dissolved oxygen (DO) is one of the important technical parameters affecting the HLB-MR performance. Current reports describing the effects of $\mathrm{DO}$ on bioflocculation and membrane fouling mainly focus on conventional biotreatment technologies such as sequencing batch reactor (SBR) and membrane bioreactor (MBR) under long SRT and HRT [11,12]. In comparison, only a few studies have focused on the effect of DO on bioflocculation in MBR under short SRT and HRT for the concentration and recovery of organic matter from sewage. Faust et al. studied the effect of DO concentration on the bioflocculation process in HLB-MR [13]. However, the adopted reactor in their experiment was rectangular and constructed on flat-sheet microfiltration (MF) membranes. Meanwhile, there were no reports describing the mechanism of DO's influence on bioflocculation and membrane fouling from the perspective of a microbial population. In comparison, the adopted reactor in this study was circular and developed on a hollow-fiber ultrafiltration (UF) membrane module. It had a larger packing density for the membrane module as well as a stronger sewage treatment capacity, which boasts a promising application prospect.

With variations in the quality of the influent water, the effect of DO on the performance of the HLB-MR on flocculating organic matter in municipal wastewater of organics may be very different. In this study, real urban sewage in northern China was selected as the treatment object. A comparative analysis was undertaken to measure the concentration and recovery efficiency of organic matter, bioflocculation performance, and membrane fouling in the HLB-MR under DO concentrations of 1-2 $\mathrm{mg} / \mathrm{L}$ (LDO reactor) and 6-8 $\mathrm{mg} / \mathrm{L}$ (HDO reactor), respectively. The purpose of the HDO reactor is to prevent the anaerobic zone from inhibiting the biological flocculation process. The LDO reactor is considered to be consistent with the DO parameters of the actual sewage treatment plant operation control. This study detected and compared the floc particle size distribution, EPS content, metal cation concentration, and microbial community structure in the two reactors under different DO concentrations. This study aimed to illustrate the effect of DO on bioflocculation and membrane fouling in an HLB-MR of novel structure and the mechanism behind such effect. It will probably provide theoretical support for the practical application of this technology in the future.

\section{Materials and Methods}

\subsection{Experimental Setup and Operation Parameters}

The experimental setup is shown in Figure 1. After the sewage is evenly mixed in the raw tank, it is controlled by the peristaltic pump to enter the LDO reactor and the HDO reactor, respectively, and were kept running in parallel. The HDO reactor was completely aerated by air, and the aeration flow was adjusted by a gas flowmeter. On the other hand, the LDO reactor was under mixed nitrogen-air gas aeration, and the mixing ratio is adjusted through the gas valve. In order to ensure the availability of identical gas shear force in the two reactors, the mixed gas for the LDO reactor and air for the HDO reactor were maintained at the same flow rate. The effluents of these reactors were 
sucked by a peristaltic pump controlled at a cyclic pumping mode of $10 \mathrm{~min}$ ON and $3 \mathrm{~min}$ OFF by time relay and operated in constant flux mode. The effluent flux was controlled to ensure that the HRTs of both reactors were $1 \mathrm{~h}$. The concentrate output was regulated by a peristaltic pump to ensure that the SRTs of both reactors were $0.6 \mathrm{~d}$. Moreover, the transmembrane pressure (TMP) of the two reactors was transmitted via a pressure sensor to a computer where data were recorded in real time.

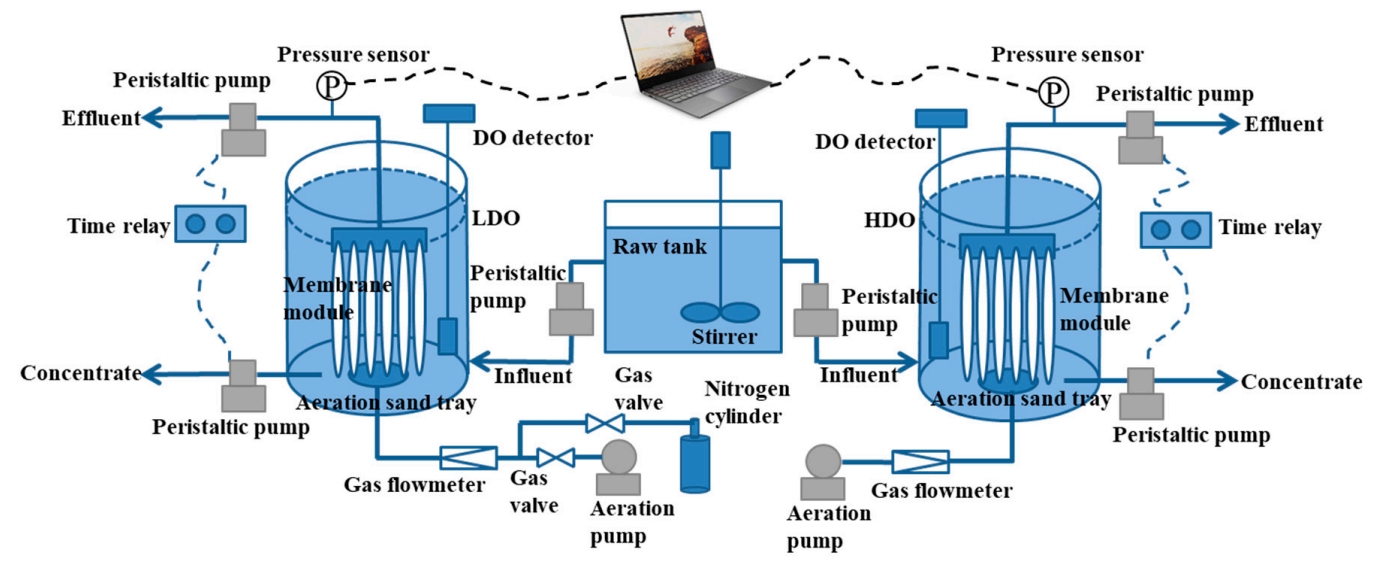

Figure 1. Schematic of experimental setup.

In this study, the sewage was taken from the grit chamber of the south sewage treatment plant with a treatment capacity of 150,000 $\mathrm{m}^{3} / \mathrm{d}$ in Changchun, Jilin Province. After collection, the sewage was stored at $4{ }^{\circ} \mathrm{C}$ for no more than three days. Before fed into the raw tank, the sewage was filtered through a sieve with a pore size of $3 \mathrm{~mm}$ and was adjusted to room temperature (about $20^{\circ} \mathrm{C}$ ). The quality of the sewage is shown in Table 1.

Table 1. Influent characteristics of high-loaded bioflocculation membrane reactor (HLB-MRs) unit: mg/L.

\begin{tabular}{ccccc}
\hline Chemical Oxygen Demand (COD) & $\mathbf{N H}_{\mathbf{4}}{ }^{+}-\mathbf{N}$ & $\mathbf{T N}$ & $\mathbf{T P}$ & $\mathbf{S S}$ \\
\hline $351 \pm 21$ & $26 \pm 4$ & $30 \pm 6$ & $0.5 \pm 0.08$ & $500 \pm 132$ \\
\hline
\end{tabular}

\subsection{Samples and Analysis}

Since reactors typically do not stabilize before operating for as long as three SRTs, two reactors were run in parallel for $15 \mathrm{~d}$. Sampling analysis was conducted on the influent, concentrate, and effluent of the reactors on the 13th, 14th, and 15th day, respectively. Three parallels were taken for each sample.

COD Measurement: COD in the samples was classified into four classes: total COD (CODTO), suspended $\mathrm{COD}\left(\mathrm{COD}_{\mathrm{SS}}\right)$, colloidal $\mathrm{COD}\left(\mathrm{COD}_{\mathrm{CO}}\right)$, and solvent $\mathrm{COD}\left(\mathrm{COD}_{\mathrm{SO}}\right)$. $\mathrm{COD}_{\mathrm{TO}}$ was from the samples measured directly, $\mathrm{COD}_{\mathrm{CO}}$ was the $\mathrm{COD}$ difference between the filtrates draining through the filter paper, and the permeates of the membrane $(0.45 \mu \mathrm{m})$. COD SO $_{\text {was }}$ equal to COD in the membrane $(0.45 \mu \mathrm{m})$ permeates. The measurement of COD was conducted according to the standard method [14].

EPS measurement: $30 \mathrm{~mL}$ of the reactor concentrate was placed in a centrifuge tube and was centrifuged at $12,000 \times g$ for $5 \mathrm{~min}$. The supernatant was then drained through a $0.45-\mu \mathrm{m}$ membrane filter. EPS measured in this permeate was denoted as the 'free EPS'. The remaining sludge in the centrifuge tube was brought to its original volume with pure water; the mixture was then placed in a water bath at $80^{\circ} \mathrm{C}$ for $30 \mathrm{~min}$. After the centrifuge tube was cooled, the refilled mixture was centrifuged at $12,000 \times \mathrm{g}$ for $5 \mathrm{~min}$. The supernatant was then drained through a $0.45-\mu \mathrm{m}$ membrane filter and EPS measured in this permeate was the 'bound EPS'. Proteins in the free EPS and bound EPS were determined by a modified Lowry method [15] and polysaccharides by the anthrone colorimetric technique [16].

Metal ion measurement: The supernatant of the concentrated sample was obtained after $30 \mathrm{~min}$ of precipitation. The metal ions (magnesium, calcium, and aluminum) were then measured by ICP-OES 
(Inductively coupled plasma-optical emission spectrometry) (Perkin Elmer, Optima 5300 DV) after the supernatant was filtered through a $0.45 \mu \mathrm{m}$ filter membrane. A certain amount of precipitate in the concentrated liquid was allowed to freeze dry. A known weight of this freeze-dried solid was added into a Poly tetra fluoroethylene (PTFE) tube followed by the addition of $10 \mathrm{~mL}$ of $65 \% \mathrm{HNO}_{3}$. The tube was then placed on a graphite digestion apparatus (SCP Science, DigiPREP MS) for digestion at $180^{\circ} \mathrm{C}$ for $45 \mathrm{~min}$. Thereafter, the acid was removed to keep the volume of the remaining liquid at about $1 \mathrm{~mL}$. After cooling to room temperature, the liquid was washed with $2 \%$ of $\mathrm{HNO}_{3}$, filtered, and diluted to $50 \mathrm{~mL}$. Finally, it was measured by ICP-OES (Perkin Elmer, Optima 5300 DV) for the detection of metal ions (magnesium, calcium, and aluminum).

Measurement of turbidity, DO, and floc size: After $30 \mathrm{~min}$ of precipitation, the supernatant of the concentrate was collected, and its turbidity determined by a turbidimeter (Hach, 2100Q). The DO concentration in the two reactors was measured by a dissolved oxygen meter (WTW, Oxi 3310-SET 1). The floc size of the concentrated sample was measured using the laser particle size and shape analyzer (EyeTech), with the results recorded in the form of number size distribution.

High-throughput sequencing: On the 15th day of operation of the reactor, samples were withdrawn from the concentrate as well as from the influent of the two reactors, and the concentrate was precipitated for $30 \mathrm{~min}$. Samples of the supernatant, the precipitate, and the influent were used for DNA extraction and high-throughput sequencing. The FastDNA Spin Kit for Soil (Qbiogene Inc., Carlsbad, CA, USA) was used to extract the total DNA of the samples. The V3 and V4 regions of the $16 \mathrm{~S}$ rRNA gene were amplified by the forward 338F (5'-ACTC CTAC GGGA GGCA GCAG-3') and reverse 806R (5'-RGGA CTAC HVGG GTWT CTAAT-3') primers [17]. The 20- $\mu$ L PCR amplification system was adopted and configured as follows: 5X FastPfu polymerase Buffer, $4 \mu \mathrm{L} ; 2.5 \mathrm{mM}$ of each dNTP, $2 \mu \mathrm{L}$ each (total, $8 \mu \mathrm{L})$; Forward Primer $(5 \mu \mathrm{M}), 0.8 \mu \mathrm{L}$; Reverse Primer $(5 \mu \mathrm{M}), 0.8 \mu \mathrm{L}$; FastPfu Polymerase, $0.4 \mu \mathrm{L}$; BSA, $0.2 \mu \mathrm{L}$; sample DNA, $10 \mathrm{ng}$, and final volume brought to $20 \mu \mathrm{L}$ with ddH2O. The reaction in the PCR machine (ABI GeneAmp ${ }^{\circledR}$ t9700) was performed under the following conditions: preheating at $95^{\circ} \mathrm{C}$ for $3 \mathrm{~min}$, followed by 30 cycles of amplification (denaturation at $95^{\circ} \mathrm{C}$ for $30 \mathrm{~s}$, annealing at $55^{\circ} \mathrm{C}$ for $30 \mathrm{~s}$, extension at $72{ }^{\circ} \mathrm{C}$ for $45 \mathrm{~s}$, extension at $72{ }^{\circ} \mathrm{C}$ for $10 \mathrm{~min}$, and the temperature kept at $72{ }^{\circ} \mathrm{C}$ till termination). The amplified samples were sequenced by the Illumina MiSeq sequencer.

\section{Results and Discussion}

\subsection{Concentration and Recovery of Organic Matter}

Test results for each grade of COD in the influent, concentrate, and effluent in the two reactors are presented in Table 2. It can be seen that concentration multiples of the concentrated $\mathrm{COD}_{\mathrm{TO}}$ relative to the influent $\mathrm{COD}_{\mathrm{TO}}$ in the $\mathrm{LDO}$ and $\mathrm{HDO}$ reactors were about 10 and 12 , respectively. The concentration multiple of the CODss relative to influent $\mathrm{COD}_{\mathrm{TO}}$ were about 15.7 (LDO) and 13.6 (HDO). This indicated that the HDO reactor concentrated with a better effect than the LDO reactor. The concentration multiple of CODss in both reactors were higher than that of $\mathrm{COD}_{\mathrm{TO}}$, indicating that bioflocculation occurred in both reactors. The $\mathrm{COD}_{\mathrm{CO}}$ concentration multiple of around 1.6 in the HDO reactor was lower than that in the LDO reactor (about 2.5). This suggested that more colloidal COD were converted to suspended COD in the HDO reactor. This further proved that the organic matter was concentrated with stronger flocculation in the HDO reactor.

Table 2. Classified COD concentration of influent, concentrate and effluent unit: mg/L.

\begin{tabular}{rccccc}
\hline & & COD $_{\text {ss }}$ & COD $_{\text {CO }}$ & COD $_{\text {SO }}$ & COD $_{\text {TO }}$ \\
\hline influent & & $258 \pm 21$ & $48 \pm 5$ & $45 \pm 3$ & $351 \pm 21$ \\
\hline \multirow{2}{*}{ LDO (1-2 mg/L) } & $\begin{array}{c}\text { concentrate } \\
\text { effluent }\end{array}$ & $3510 \pm 238$ & $120 \pm 13$ & $69 \pm 8$ & $3699 \pm 312$ \\
& & & & $34 \pm 5$ \\
\hline \multirow{2}{*}{ HDO (6-8 mg/L) } & $\begin{array}{c}\text { concentrate } \\
\text { effluent }\end{array}$ & $4049 \pm 335$ & $75 \pm 8$ & $62 \pm 6$ & $4186 \pm 336$ \\
& & & & $29 \pm 3$ \\
\hline
\end{tabular}


The $\mathrm{COD}_{\mathrm{TO}}$ mass balance analysis of the measurement data is shown in Figure 2. It can be seen that the fractions of both the lost $\mathrm{COD}_{\mathrm{TO}}$ and the effluent $\mathrm{COD}_{\mathrm{TO}}$ were higher in the $\mathrm{LDO}$ reactor than that in the $\mathrm{HDO}$ reactor. Hence, the fraction of the $\mathrm{COD}_{\mathrm{TO}}$ distributed to the concentrate was lower in the LDO reactor than that in the HDO reactor. Nevertheless, the value was still over $70 \%$. This meant that the LDO reactor could still achieve an ideal concentration and recovery effect of the organic matter.

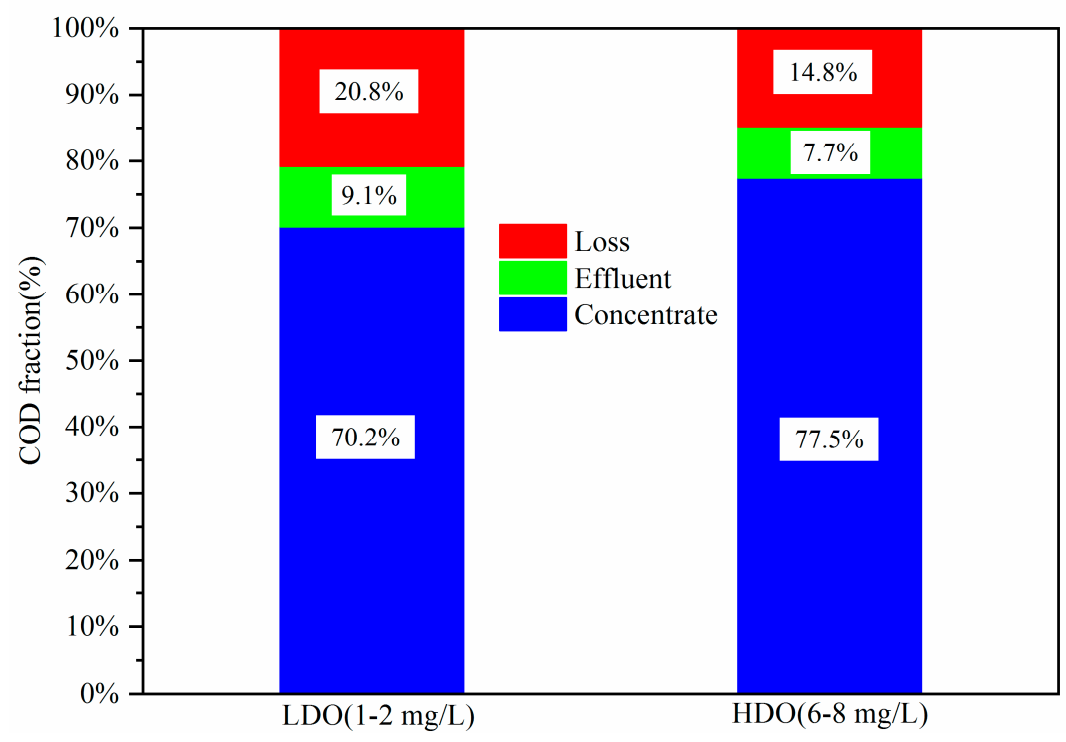

Figure 2. $\mathrm{COD}_{\mathrm{TO}}$ mass balance at different $\mathrm{DO}$ concentrations.

\subsection{Bioflocculation}

As shown in Table 2 and Figure 3, the fractions of $\mathrm{COD}_{S \mathrm{SS}}$ and $\mathrm{COD}_{\mathrm{CO}}$ in the influent were $73.5 \%$ and $13.7 \%$, respectively. The values for these parameters in the concentrates in the LDO reactor were $94.9 \%$ and $3.2 \%$, respectively; and in the HDO reactors were $96.7 \%$ and $1.8 \%$, respectively. This indicated that a large proportion of $\mathrm{COD}_{\mathrm{CO}}$ was converted to $\mathrm{COD}_{\mathrm{SS}}$ in the two reactors. The flocculation efficiency of the LDO and HDO reactors calculated from the mass loading of $\mathrm{COD}_{\mathrm{CO}}$ in the influent and the concentrate was $83 \%$ and $89 \%$, respectively; the concentrate turbidity in the LDO and HDO reactors was 32 NTU and 27 NTU, respectively. Thus, these data confirmed that the HDO reactors had a better bioflocculation effect.

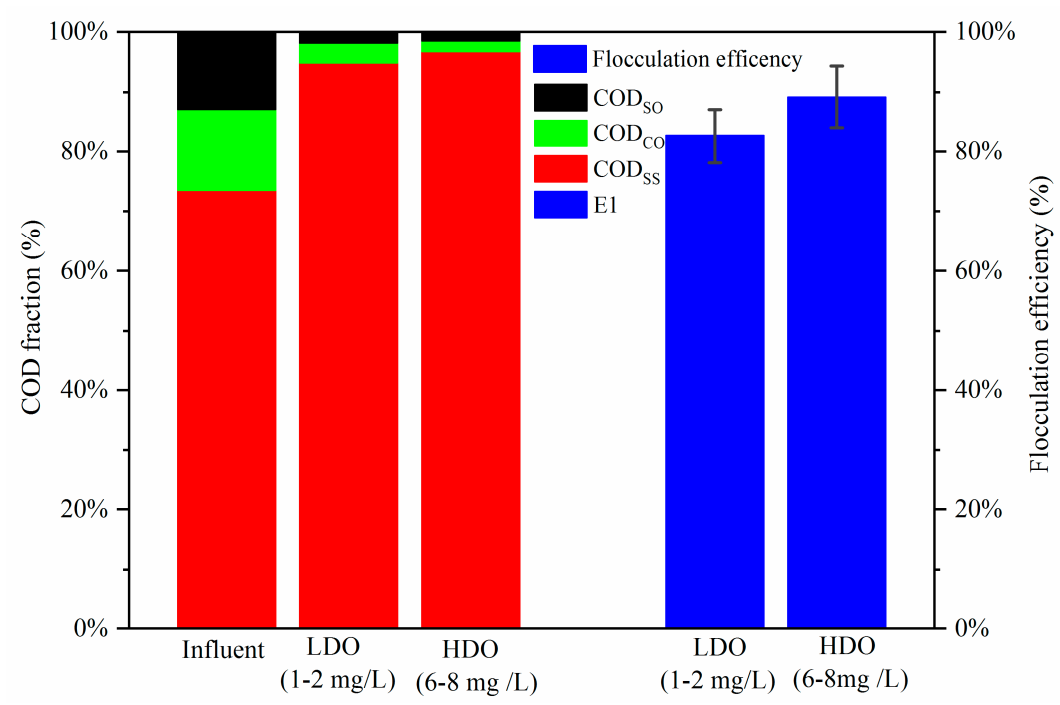

Figure 3. Fraction of different classified COD and flocculation efficiency of HLB-MRs at different DO concentrations. 
The concentration of the particles in the concentrates of both the reactors was $2.2 \times 10^{5} / \mathrm{mL}$ each. The proportion of the particles with different size ranges in the concentrates is shown in Figure 4. In the HDO reactor, the proportion of particles in size range of $0-1 \mu \mathrm{m}$ was $26.2 \%$, which was significantly higher than that in the LDO reactor (19.0\%). However, the proportions of particles in the sizes ranging from $1-10 \mu \mathrm{m}$ and $10-30 \mu \mathrm{m}$ were $58.4 \%$ and $14.3 \%$, respectively, in the HDO reactor. Both these values were lower than those observed in the LDO reactor $(64.4 \%$ and $15.6 \%$, respectively). The number of particles in a size range of 30-100 $\mu \mathrm{m}$ was small in each reactor, and there was no significant difference between the two reactors. Compared with the LDO reactor, in the HDO reactor, the concentrate had a higher proportion of particles in a size range of $0-1 \mu \mathrm{m}$, but a lower proportion of particles in a size range of 30-100 $\mu \mathrm{m}$. This may be attributed to the fact that a very high DO concentration induced the deflocculation in the HLB-MR, which disintegrated the larger particles in the reactor concentrate into smaller ones and thus increased the proportion of the smaller particles. DO is an important parameter affecting the properties of sludge flocs and has been greatly studied by scholars [18-20]. However, the mechanism behind the effect of a DO concentration over $5 \mathrm{mg} / \mathrm{L}$ on sludge floc size is yet unclear and warrants further study.

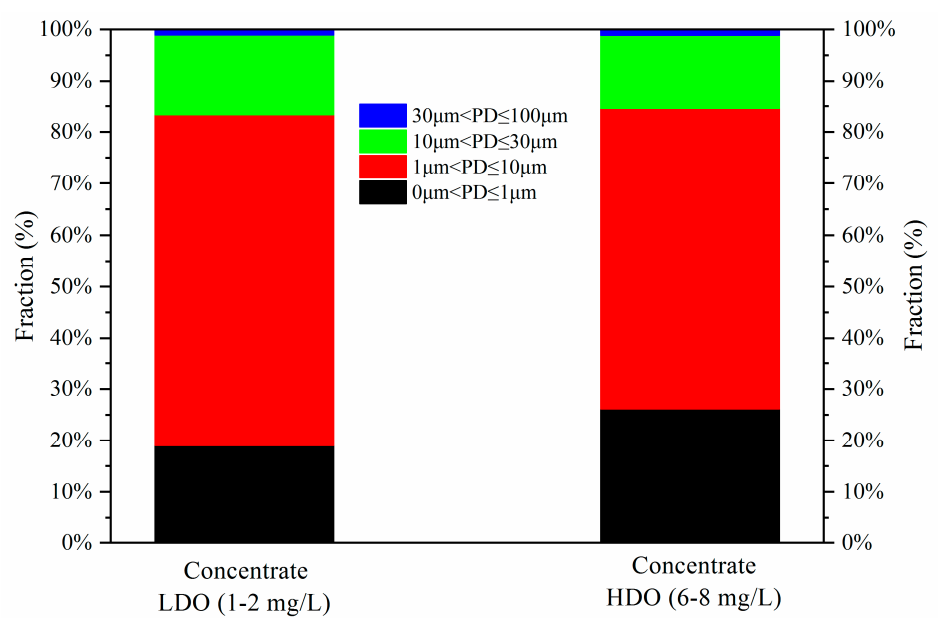

Figure 4. Proportion of particles in different particle size interval of concentrate at different DO concentrations.

Regarding the DO effect on bioflocculation efficiency, similar results were reported by Faust et al., where the bioflocculation efficiency at a DO concentration of $4 \mathrm{mg} / \mathrm{L}(92 \%)$ was considerably higher than that at a DO concentration of $1 \mathrm{mg} / \mathrm{L}(69 \%)$ [13]. However, what was less similar to this paper, in their report, was that they found no significant difference between the flocculation efficiency of the LDO reactor and the HDO reactor; both displayed efficiencies above $80 \%$. Moreover, their report describing DO effect on particle size distribution in the reactor concentrates was in contrast to what was observed in this paper. This was probably because the influent quality and the reactor structure adopted were not the same as those adopted by the experiment of this paper. The literature provides the following explanations for the unpleasant flocculation effect of organic matter in an activated sludge system under low DO concentration: (1) EPSs would act on bioflocculation, but the lower aerobic activity at low DO concentration may decrease the production rate or increase the anaerobic degradation rate of EPSs [21-23]. (2) $\mathrm{Fe}^{3+}$ produces a stronger cationic bridging effect with the EPSs of the microorganisms than $\mathrm{Fe}^{2+}[24,25]$. Therefore, at low DO concentrations, the microorganisms reduce $\mathrm{Fe}^{3+}$ to $\mathrm{Fe}^{2+}$, and thus cause deflocculation. (3) Filamentous bacteria that begin to overgrow under a low DO concentration impose a negative effect on flocculation [26]. Considering that the DO concentration was not controlled at the same level, and also the related environmental factors (such as sludge concentration, temperature, $\mathrm{pH}$, and substrate composition) were different in the above reports, the optimal range of $\mathrm{DO}$ concentration for control is only for reference purposes. However, for bioflocculation in the HLB-MR reactor without deliberate sludge inoculation and with a very short SRT 
and HRT, further study is warranted to observe whether the mechanism behind the DO concentration effect on the process is the same.

\subsection{EPS and Metal Cation Concentration}

EPSs in the precipitate and the supernatant of the concentrate are referred to as bound EPS and free EPS, respectively. The total EPS consists of EPS-Protein and EPS-Polysaccharide. As shown in Figure $5,77.0 \%$ of the total EPS in the LDO reactor existed in the bound form and $23.0 \%$ in the free form; in the HDO reactor, $79.9 \%$ was in the bound form, and $20.1 \%$ existed as free EPS. Therefore, the content of bound EPS was over three times that of free EPS for both the reactors; this made the bound EPS the main existing form of total EPS. The literature reports indicate that bioflocculation of particles in sewage is mainly accredited to the EPSs secreted by the microorganisms [27]; EPS forms an interconnected substrate between the particles [18] because of its viscous effect. Moreover, a higher content of bound EPS in the precipitate accounts for the occurrence of extensive bioflocculation in the two reactors. In the HDO reactor, the contents of bound and free EPS were $15.64 \mathrm{mg} /(\mathrm{g}$.VSS) and $8.71 \mathrm{mg} / \mathrm{L}$, respectively; these values were significantly higher than those in the LDO reactor $(11.83 \mathrm{mg} /(\mathrm{g} \cdot \mathrm{VSS})$ and $6.56 \mathrm{mg} / \mathrm{L}$, respectively). This indicated that a higher concentration of EPS was generated at a higher DO concentration in the HBMR. Studies have reported that the functional groups of EPS, e.g., amino, carboxyl, and phosphate groups, could promote the flocculation of sewage particles and maintain the stability of the flocs $[28,29]$. In both the reactors, the free EPS consisted of only EPS-Polysaccharide; EPS-Protein was absent. In the bound EPS fraction of the two reactors, the EPS-Protein constituted 12.3\% (HDO) and 19.0\% (LDO), respectively. These values were far less than the percentage (50\%) of EPS-Polysaccharide present, indicating that the content of EPS-Protein was lower than that of EPS-Polysaccharide and mainly existed in the sludge substrate. However, other studies have reported EPS-Protein as being the main component of total EPS in sludge and biofilms [30,31]. The differences in the observations may be due to differences in the experimental water quality and EPS extraction methods.

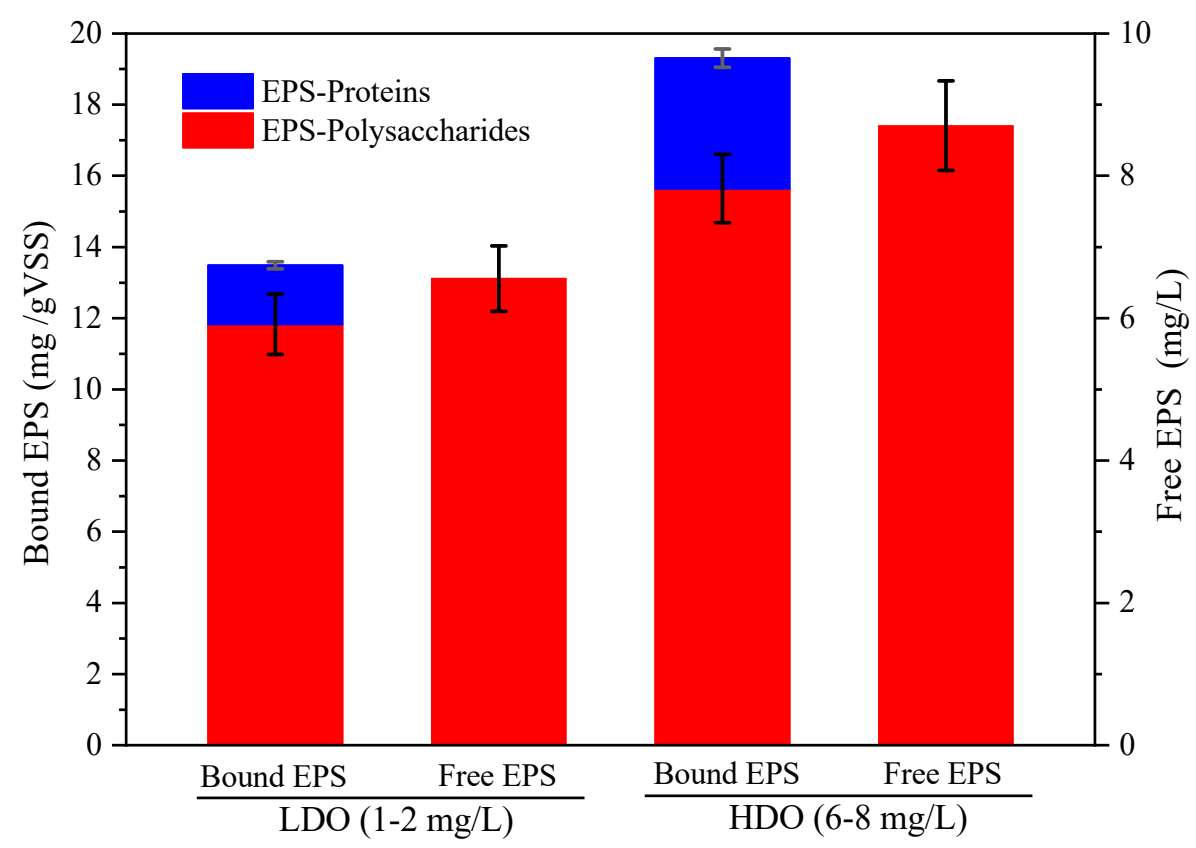

Figure 5. Bound extracellular polymer substance (EPS), free EPS, EPS-Protein and EPS-Polysaccharide concentrations in the concentrate and the supernatant at different dissolved oxygen (DO) concentrations.

Table 3 shows the concentration of the multivalent metallic cations $\mathrm{Ca}^{2+}, \mathrm{Mg}^{2+}, \mathrm{Al}^{3+}$, and $\mathrm{Fe}^{3+}$ in the precipitate and the supernatant of the concentrates. In the precipitate fraction, calcium was the highest in concentration, followed by aluminum, iron, and magnesium; both calcium and aluminum 
were more than twice the concentration of magnesium. Among these four cations, magnesium, aluminum, and iron were significantly higher in the concentrates precipitate in the HDO reactor than in the LDO reactor. However, this difference in calcium concentration was not significant. On the other hand, in the supernatant, magnesium and iron were extremely low in content and presented only a minimal difference between the two reactors. In comparison, the concentrations of calcium and aluminum were significantly lower in the HDO reactor than in the LDO reactor. The above data indicated that more cations were distributed to the solid fraction of the concentrate in the HDO reactor than in the LDO reactor. This observation was consistent with the fact that the concentration of bound EPS was higher in the HDO reactor. This may result from the fact that polyvalent metallic cations bridged with EPSs and were embedded in the concentrate sludge substrate. The bioflocculation mechanism is often explained by the Electric Double-Layer (EDL) theory of interaction, Ion Bridging theory, and Alginate theory [32,33]. It has been widely proved by scholars that polyvalent metal ions facilitate the bioflocculation process. Jin et al. [34], through their research on seven sewage treatment plants, found that the increase in the metal cation concentration could improve the settleability and compressibility of sludge. Wen et al. [35] reported that a higher concentration of $\mathrm{Al}^{3+}$ could improve the flocculation performance of activated sludge. Bruus et al. [36] found that the discharge of $\mathrm{Ca}^{2+}$ dispersed the activated sludge flocs. In the experiment of this study, the concentration data on calcium, magnesium, aluminum, and iron in the supernatant and the concentrate fractions also showed that magnesium, calcium, and iron ions formed stronger bonds with solid sludge substrate and did not easily separate from the precipitate into the supernatant. However, the aluminum ions were more likely to be distributed into the supernatant. This observation was likely due to the reason that the precipitate formed by flocculation of aluminum ions was vulnerable to environmental factors such as $\mathrm{pH}$ value, shear force, etc.

Table 3. $\mathrm{Ca}^{2+}, \mathrm{Mg}^{2+}, \mathrm{Al}^{3+}$ and $\mathrm{Fe}^{3+}$ concentration in the supernatant and concentrate of the HLB-MRs.

\begin{tabular}{ccccccccc}
\hline & \multicolumn{3}{c}{$\begin{array}{c}\text { Supernatant Concentration } \\
(\mathbf{m g} / \mathrm{L})\end{array}$} & \multicolumn{4}{c}{$\begin{array}{c}\text { Sediments Concentration } \\
\text { (mg/gTSS) }\end{array}$} \\
\hline & $\mathrm{Ca}^{2+}$ & $\mathrm{Mg}^{2+}$ & $\mathrm{Al}^{3+}$ & $\mathrm{Fe}^{3+}$ & $\mathrm{Mg}^{2+}$ & $\mathrm{Al}^{3+}$ & $\mathrm{Ca}^{2+}$ & $\mathrm{Fe}^{3+}$ \\
\hline $\mathrm{LDO}(1-2 \mathrm{mg} / \mathrm{L})$ & 6.4 & 0.16 & 27.10 & 0.06 & 17.31 & 6.09 & 14.93 & 10.31 \\
\hline $\mathrm{HDO}(6-8 \mathrm{mg} / \mathrm{L})$ & 5.2 & 0.17 & 25.20 & 0.1 & 17.26 & 6.47 & 17.01 & 10.6 \\
\hline
\end{tabular}

\subsection{Analysis of Membrane Fouling}

The TMP of the membranes in the LDO and HDO reactors after removal of the effluent through the pumps is shown in Figure 6. In the first $24 \mathrm{~h}$, the TMP of the two reactors grew at a slow and almost identical rate. The value was also low (up to $5 \mathrm{kPa}$ ). This may be related to the fact that the reactors were at the beginning of the operation, hence, no serious membrane fouling had been formed. However, the TMP in the HDO reactors began to grow at a significantly higher rate than in the subsequent LDO reactors, and the difference between their rates began increasing. When the operation came to its 100th $\mathrm{h}$, the TMP of the HDO reactor was close to $30 \mathrm{kPa}$, indicating that simple suction-suspension of the pump could not meet the requirement to remove the membrane surface fouling. Later, the membrane module was removed from the HDO reactor, and its surface was washed with clean water before it was inserted into the reactor again. It was observed that the TMP immediately dropped back to about $3 \mathrm{kPa}$, showing that the membrane fouling had been removed. However, the TMP in the LDO reactor had only increased to about $22 \mathrm{kPa}$; it finally reached about $30 \mathrm{kPa}$ after the reactor had continued operation for $130 \mathrm{~h}$ without cleaning. The TMP reflected the membrane fouling of the two reactors on a macro level. Figure 6 shows that the membrane fouling in the HDO reactor was more serious than that in the LDO reactor. 


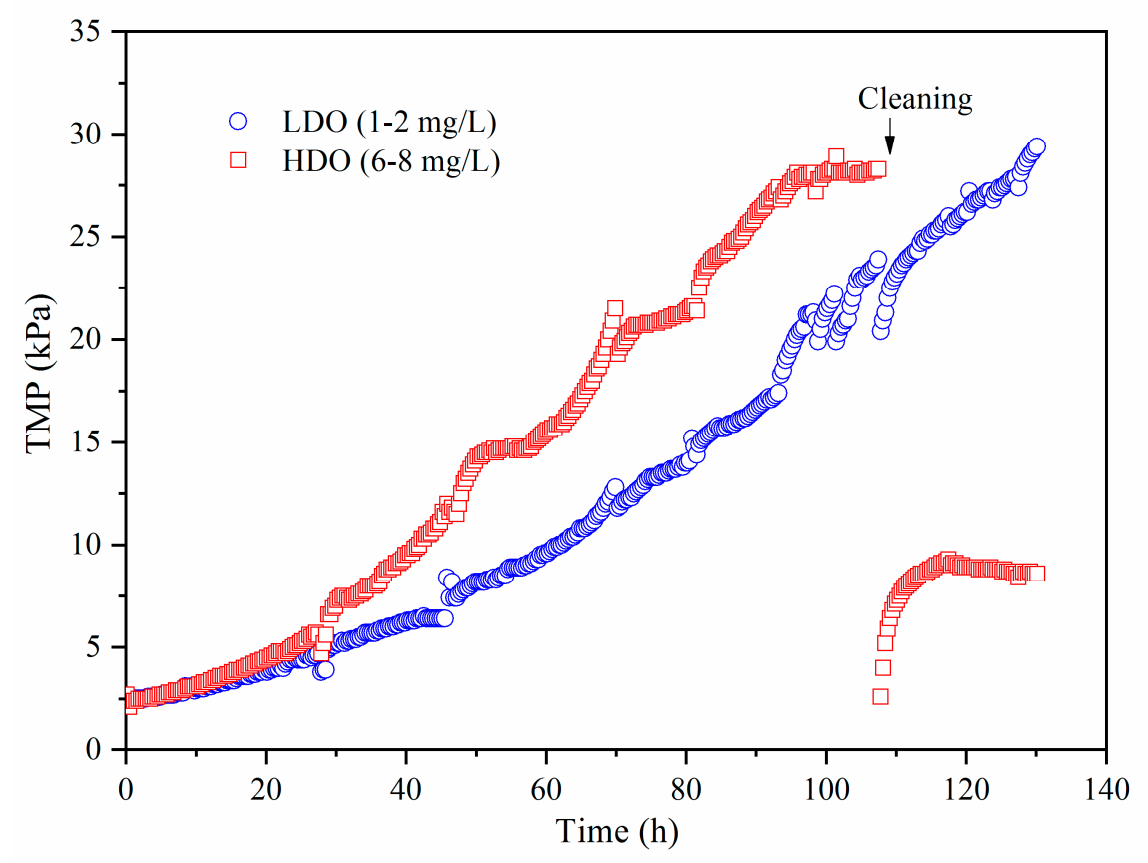

Figure 6. Development of the transmembrane pressure (TMP) of HLB-MRs at different DO concentrations.

From the above analysis, we can conclude that operation under the HDO reactor did not mitigate the membrane fouling but exacerbated it in comparison with the situation under the LDO reactor. However, Faust et al. [13] reported that the membrane fouling potential of the reactor concentrate was lower when the DO concentration was $4 \mathrm{mg} / \mathrm{L}$ (higher at the DO concentration of $1 \mathrm{mg} / \mathrm{L}$ ). Jin et al. [37] studied the effect of DO concentration on the membrane filtration characteristics of immersed MBR and also found that the membrane filtration characteristics of the MBR were better when the DO concentration was controlled above $3 \mathrm{mg} / \mathrm{L}$ than when the DO concentration was below $0.1 \mathrm{mg} / \mathrm{L}$. The results obtained in this paper differ from those reported in the above studies, probably because excessive DO resulted in the deflocculation of the sludge floc particles, which meant that the number of tiny particles (below 1 micron) in the HDO reactor concentrates was greater than that in the LDO reactor. The literature reports presented a strong positive correlation between the concentration of submicron particles $(<450 \mathrm{~nm})$ and membrane fouling [38,39]. Moreover, the differences in the solid concentration, concentrate viscosity, and EPS content between the two reactors may also contribute remarkably to the different degrees of membrane fouling [40,41].

\subsection{Structural Characteristics of the Microbial Community}

High-throughput sequence analysis was performed for five samples that included the influent (Wastewater), supernatant from the LDO reactor (LDO-S), supernatant from the HDO reactor (HDO-S), residual precipitate in the LDO reactor (LDO-R), and residual precipitate in the HDO reactor (HDO-R). Analysis of the relative abundance of various bacterial phyla in these five samples showed that Proteobacteria dominated all the samples; this observation was consistent with previous reports $[42,43]$. The Proteobacteria were further classified at the class level, and their relative abundance distribution is shown in Figure 7. In all the five samples, the Betaproteobacteria presented the largest relative abundance with the highest dominance: it was $46.26 \%$ in wastewater, $74.47 \%$ in the LDO-S, $76.14 \%$ in the HDO-S, 56.24\% in the LDO-R, and 50.96\% in the HDO-R samples. The Gammaproteobacteria were the second-most abundant community in the samples of the supernatant and the precipitate. Their abundance was $17.86 \%$ in the LDO-S, $19.40 \%$ in the HDO-S, $25.24 \%$ in the LDO-R, and $27.34 \%$ in the HDO-R samples. The relative abundance of the Epsilonproteobacteria was low in all samples, with most of them being less than $2 \%$. In the two precipitate samples, the abundance of Deltaproteobacteria was $5.39 \%$ (LDO-R) and $8.27 \%$ (HDO-R). However, their relative abundance was below $1 \%$ in 
the supernatant samples. The relative abundance of the Alphaproteobacteria in the influent sample was as high as $27.12 \%$; this value was higher in the precipitate compared to that in the supernatant sample. When the DO concentration increased, the relative abundance of Betaproteobacteria decreased significantly in the precipitate sample and increased slightly in the supernatant sample. This indicated that, under increased DO concentrations, the Betaproteobacteria were replaced by other bacteria of a relatively low growth rate and excellent substrate affinity. However, the relative abundance of the Gammaproteobacteria in the precipitate and supernatant samples increased under a higher DO concentration, indicating that this group of bacteria had a better substrate affinity. Under higher DO concentrations, the relative abundance of Deltaproteobacteria increased in the precipitate and was greater than that in the supernatant sample. This indicated that a higher DO concentration promoted the flocculation process of these bacteria. However, the distribution of the relative abundance of Epsilonproteobacteria displayed a trend opposite to that of Deltaproteobacteria, probably because the former had a lesser capability of flocculation and was more likely to separate from sludge.

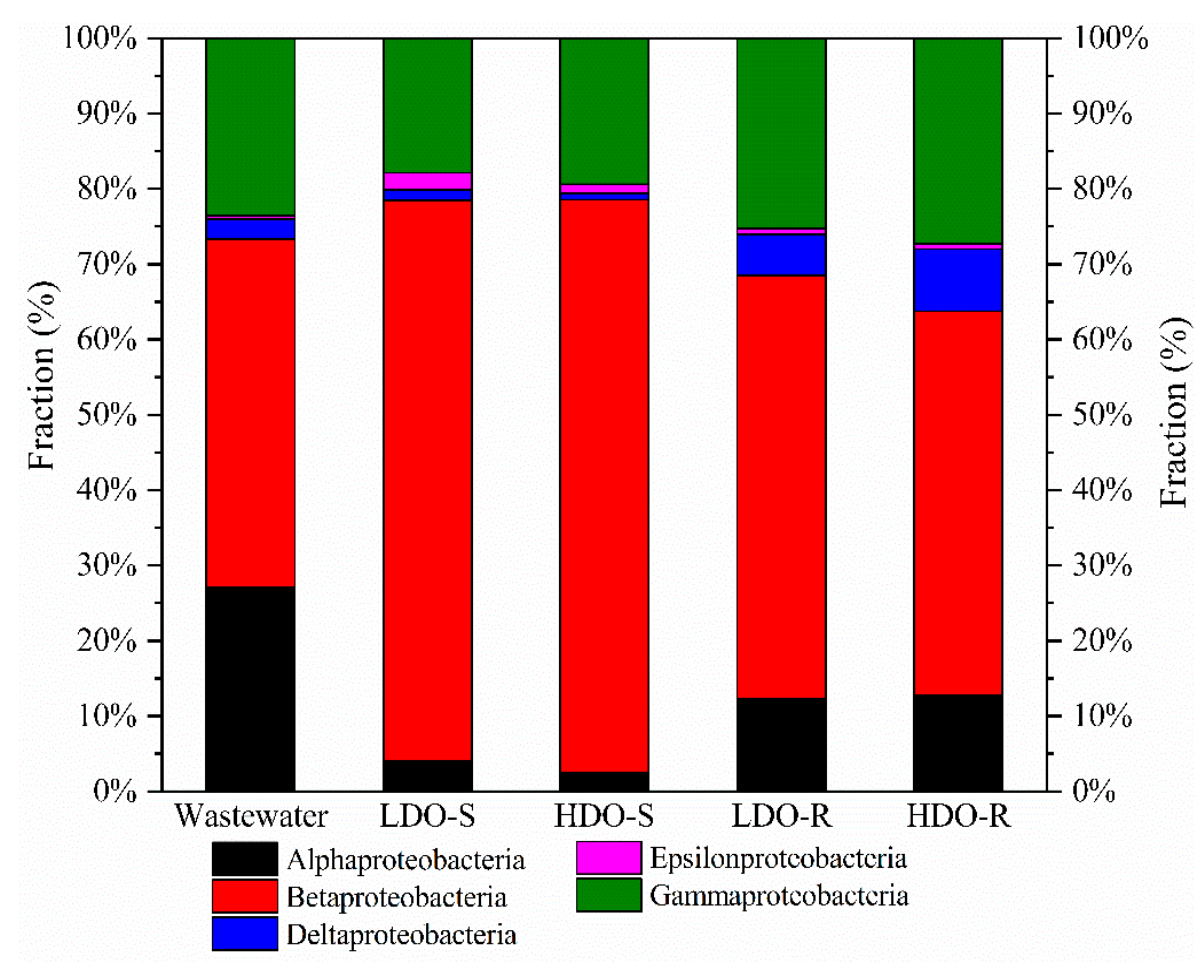

Figure 7. Relative abundance distribution of Proteobacteria at the class level of five samples.

The bacteria of the five samples were classified at the genus level, and the heatmap analysis was recorded for the top 50 abundant bacteria. As shown in Figure 8, the heatmap could analyze the similarities and differences among the bacteria. It can be seen from the figure that, at the genus level, the differences among the supernatant, influent, and precipitate samples were significant. The result of cluster analysis showed that samples of LDO-S and HDO-S gathered into one group, while those of Wastewater, LDO-R, and HDO-R gathered into another. The dominant bacteria in the supernatant sample were norank_p_Saccharibacteria, norank_f_Neisseriaceae, and 12up. Trichococcus, Ornithinibacter, norank_f_Saprospiraceae, Flavobacterium, and Dechloromonas were dominant in the influent and the precipitate samples. Roseiflexus showed the largest significant difference in abundance in the supernatant and precipitate samples. Phytoplanktons in the supernatant may exacerbate membrane fouling, while the species in the precipitate may promote bioflocculation. Moreover, the figure also showed that the differences in the species of the supernatant and the precipitate samples in the reactors under high DO concentrations were greater than those under low DO concentrations. 


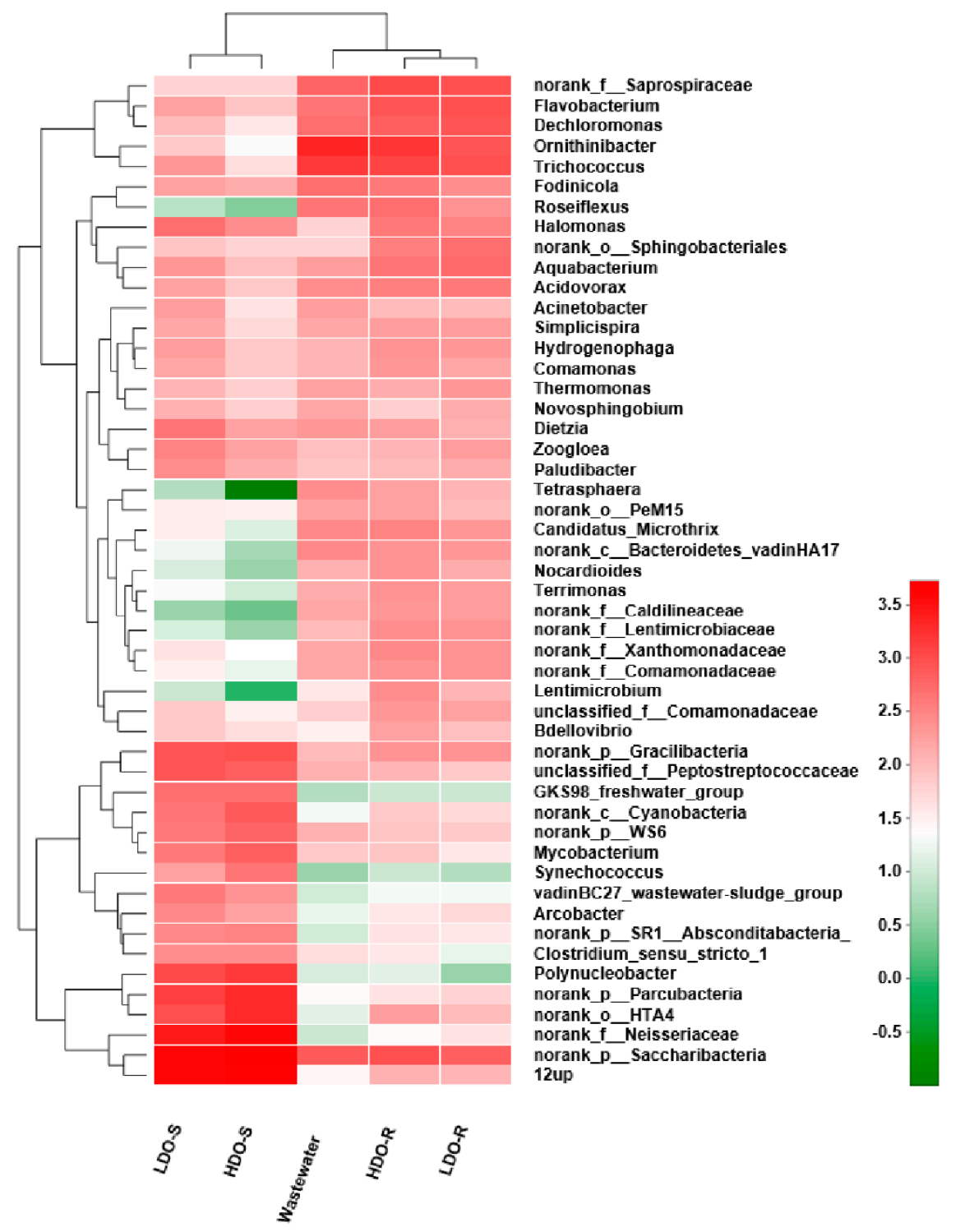

Figure 8. Heat map of species relative abundance of bacteria at genus level of five samples.

\section{Conclusions}

In this study, the influences of DO on parameters including the concentration and recovery efficiency of organic matter, bioflocculation performance, content of EPS, the concentration of metal cations, membrane fouling and microbial community structure in HLB-MR were studied. From the experiment results, we can conclude that:

(1) The recovery efficiency of organic matter in the LDO reactor was $70.2 \%$; lower than the $77.5 \%$ when the HDO reactor Nonetheless, the fractions of CODss in the concentrate of the two reactors were not significantly different, and both of them exceeded $94 \%$;

(2) The flocculation efficiency of the LDO reactor and the HDO reactor was $83 \%$ and $89 \%$, respectively. A higher DO concentration promised a more remarkable bioflocculation performance;

(3) The contents of both bound and free EPS in the HDO reactor were significantly higher than those under the LDO reactor. A similar trend was observed for the concentrations of magnesium and aluminum in the concentrate. Under high DO concentration, more metal cations were bound to EPS and fixed into the sludge substrate, which promoted the process of bioflocculation; 
(4) Membrane fouling of the HDO reactor was more serious than the LDO reactor. Excessive DO may have caused the sludge flocs in the HLB-MR to deflocculate and thus increased the number of fine particles in this reactor;

(5) Proteobacteria were dominant in the reactors. The species difference between the supernatant and the precipitate samples in the HDO reactor was lower than that at the LDO reactor. Plankton species in the supernatant such as norank_p_Saccharibacteria,norank_f_Neisseriaceae, and 12 up may increase turbidity and exacerbate membrane fouling. However, the species such as Trichococcus, Ornithinibacter, and norank_f_Saprospiraceae in the precipitate may promote bioflocculation to a greater extent.

Author Contributions: Conceptualization, L.W. and W.L.; methodology, writing-review and editing, L.W.; writing —original draft preparation, L.X.; investigation, data curation, L.Z.; supervision, project administration, funding acquisition, W.L. All authors have read and agreed to the published version of the manuscript.

Funding: This research was funded by Natural Science Foundation of Jilin Province, grant number 20180101317JC, Jilin Provincial Special Fund project for Industrial Innovation, grant number 2019C055 and Science and Technology Fund Project of Changchun Institute of Technology, grant number 320200031.

Conflicts of Interest: The authors declare no conflict of interest. The funders had no role in the design of the study; in the collection, analyses, or interpretation of data; in the writing of the manuscript, or in the decision to publish the results.

\section{References}

1. Gao, H.; Scherson, Y.D.; Wells, G.F. Towards energy neutral wastewater treatment: Methodology and state of the art. Environ. Sci. Process. Impacts 2014, 16, 1223-1246. [CrossRef]

2. Verstraete, W.; Vlaeminck, S.E. ZeroWasteWater: Short-cycling of wastewater resources for sustainable cities of the future. Int. J. Sustain. Dev. World Ecol. 2011, 18, 253-264. [CrossRef]

3. Sethunga, G.S.M.D.P.; Enis Karahan, H.; Wang, R.; Tae-Hyun, B. Wetting-and fouling-resistant hollow fiber membranes for dissolved methane recovery from anaerobic wastewater treatment effluents. J. Membr. Sci. 2020, 118621. [CrossRef]

4. Yamamura, H.; Okimoto, K.; Kimura, K.; Watanabe, Y. Hydrophilic fraction of natural organic matter causing irreversible fouling of microfiltration and ultrafiltration membranes. Water Res. 2014, 54, 123-136. [CrossRef]

5. Huang, H.; Lee, N.; Young, T.; Gary, A.; Lozier, J.; Jacangelo, J. Natural organic matter fouling of low-pressure, hollow-fiber membranes: Effects of NOM source and hydrodynamic conditions. Water Res. 2007, 41, 3823-3832. [CrossRef] [PubMed]

6. Carroll, T.; King, S.; Gray, S.R. The fouling of microfiltration membranes by nom after coagulation treatment. Water Res. 2000, 34, 2861-2868. [CrossRef]

7. Howe, K.; Marwah, A.; Chiu, K.; Adham, S. Effect of coagulation on the size of MF and UF membrane foulants. Environ. Ence Technol. 2006, 40, 7908-7913. [CrossRef] [PubMed]

8. Huang, H.; Schwab, K.; Jacangelo, J.G. Pretreatment for low pressure membranes in water treatment: A review. Environ. Sci. Technol. 2009, 43, 3011-3019. [CrossRef]

9. Yu, J.; Yang, L.; Danting, S.; Wenwen, F.; Peng-Fei, S.; Jiangyun, L.; Senlin, S. Membrane fouling in a powdered activated carbon-Membrane bioreactor (PAC-MBR) for micro-polluted water purification: Fouling characteristics and the roles of PAC. J. Clean. Prod. 2020, 277, 122341.

10. Wan, C.; Alam, M.A.; Zhao, X.-Q.; Zhang, X.-Y.; Guo, S.-L.; Ho, S.-H.; Chang, J.-S.; Bai, F.-W. Current progress and future prospect of microalgal biomass harvest using various flocculation technologies. Bioresour. Technol. 2015, 184, 251-257. [CrossRef]

11. Liao, B.; Lin, H.; Langevin, S.; Gao, W.; Leppard, G. Effects of temperature and dissolved oxygen on sludge properties and their role in bioflocculation and settling. Water Res. 2011, 45, 509-520. [CrossRef] [PubMed]

12. Tan, T.W.; $\mathrm{Ng}, \mathrm{H} . Y$. Influence of mixed liquor recycle ratio and dissolved oxygen on performance of pre-denitrification submerged membrane bioreactors. Water Res. 2008, 42, 1122-1132. [CrossRef] [PubMed]

13. Faust, L.; Temmink, H.; Zwijnenburg, A.; Kemperman, A.J.B.; Rijnaarts, H.H.M. Effect of dissolved oxygen concentration on the bioflocculation process in high loaded MBRs. Water Res. 2014, 66, 199-207. [CrossRef] [PubMed] 
14. Federation, W.E.; Association, A.P.H. Standard Methods for the Examination of Water and Wastewater; American Public Health Association (APHA): Washington, DC, USA, 2005.

15. Lowry, O.H.; Rosebrough, N.J.; Farr, L.A.; Randall, R.J. Protein measurement whit the folin phenol reagent. J. Biol. Chem. 1951, 193, 265-275.

16. Dubois, M.; Gilles, K.A.; Hamilton, J.K.; Rebers, P.A.; Smith, F. Colorimetric method for determination of sugars and related substances. Anal. Chem. 1956, 28, 350-356. [CrossRef]

17. Dennis, K.L.; Wang, Y.; Blatner, N.R.; Wang, S.; Saadalla, A.; Trudeau, E.; Roers, A.; Weaver, C.T.; Lee, J.J.; Gilbert, J.A.; et al. Adenomatous polyps are driven by microbe-instigated focal inflammation and are controlled by IL-10-producing T cells. Cancer Res. 2013, 73, 5905-5913. [CrossRef] [PubMed]

18. Wilén, B.-M.; Balmér, P. The effect of dissolved oxygen concentration on the structure, size and size distribution of activated sludge flocs. Water Res. 1999, 33, 391-400. [CrossRef]

19. Allen, D.G.; Zhang, Y. Strategies for minimizing deflocculation of biosolids due to oxygen disturbances. Water Sci. Technol. 2007, 55, 173-180.

20. Akshaykumar, S.; Ewa, G.P.; Santosh, P.; Soon, P.L.; Abdul, M.M.B.; Dominik, D.; Vistisen, B.T.; Xin, G.; Jern, N.W. Understanding and optimization of the flocculation process in biological wastewater treatment processes: A review. Chemosphere 2018, 210, 401-416.

21. Rasmussen, H.; Bruus, J.H.J.; Keiding, K.; Nielsen, P.H.R. Observations on dewaterability and physical, chemical and microbiological changes in anaerobically stored activated sludge from a nutrient removal plant. Water Res. 1994, 28, 417-425. [CrossRef]

22. Starkey, J.E.; Karr, P.R. Effect of Low Dissolved Oxygen Concentration on Effluent Turbidity. J. Water Pollut. Control Fed. 1984, 56, 837-843.

23. Wilén, B.-M.; Nielsen, J.L.; Keiding, K.; Nielsen, P.H. Influence of microbial activity on the stability of activated sludge flocs. Colloids Surf. B Biointerfaces 2000, 18, 145-156. [CrossRef]

24. Caccavo, F.; Frolund, B.; Van Ommen, K.F.; Nielsen, P.H. Deflocculation of activated sludge by the dissimilatory Fe(III)-Reducing Bacterium Shewanella alga BrY. Appl. Environ. Microbiol. 1996, 62, 1487-1490. [CrossRef] [PubMed]

25. Rasmussen, H.; Nielsen, P.H. Iron reduction in activated sludge measured with different extraction techniques. Water Res. 1996, 30, 551-558. [CrossRef]

26. Salehizadeh, H. Extracellular biopolymeric flocculants. Recent trends and biotechnological importance. Biotechnol. Adv. 2001, 19, 371-385. [CrossRef]

27. Fang, H.H.; Jia, X. Extraction of extracellular polymer from anaerobic sludges. Biotechnol. Tech. 1996, 10, 803-808. [CrossRef]

28. Eriksson, L.; Alm, B. Study of flocculation mechanisms by observing effects of a complexing agent on activated sludge properties. Water Sci. Technol. 1991, 24, 21-28. [CrossRef]

29. Liao, B.Q.; Allen, D.G.; Leppard, G.G.; Droppo, I.G.; Liss, S.N. Interparticle interactions affecting the stability of sludge flocs. J. Colloid Interface Sci. 2002, 249, 372-380. [CrossRef]

30. Urbain, V.; Block, J.; Manem, J. Bioflocculation in activated sludge: An analytic approach. Water Res. 1993, 27, 829-838. [CrossRef]

31. Wilén, B.-M.; Jin, B.; Lant, P. The influence of key chemical constituents in activated sludge on surface and flocculating properties. Water Res. 2003, 37, 2127-2139. [CrossRef]

32. Liu, X.-M.; Sheng, G.-P.; Yu, H.-Q. DLVO approach to the flocculability of a photosynthetic H2-producing bacterium, Rhodopseudomonas acidophila. Environ. Sci. Technol. 2007, 41, 4620-4625. [CrossRef] [PubMed]

33. Sobeck, D.C.; Higgins, M.J. Examination of three theories for mechanisms of cation-induced bioflocculation. Water Res. 2002, 36, 527-538. [CrossRef]

34. Park, C. Cations and Activated Sludge Floc Structure; Virginia Tech: Blacksburg, VA, USA, 2002.

35. Wen, Y.; Zheng, W.; Yang, Y.; Cao, A.; Zhou, Q. Influence of Al3+ addition on the flocculation and sedimentation of activated sludge: Comparison of single and multiple dosing patterns. Water Res. 2015, 75, 201-209. [CrossRef] [PubMed]

36. Bruus, J.H.; Nielsen, P.H.; Keiding, K. On the stability of activated sludge flocs with implications to dewatering. Water Res. 1992, 26, 1597-1604. [CrossRef]

37. Jin, Y.L.; Lee, W.N.; Lee, C.H.; Chang, I.S.; Huang, X.; Swaminathan, T. Effect of DO concentration on biofilm structure and membrane filterability in submerged membrane bioreactor. Water Res. 2006, 40, 2829-2836. [CrossRef] 
38. Faust, L.; Temmink, H.; Zwijnenburg, A.; Kemperman, A.J.B.; Rijnaarts, H.H.M. High loaded MBRs for organic matter recovery fromsewage: Effect of solids retention time on bioflocculation and on the role of extracellular polymers. Water Res. 2014, 56, 258-266. [CrossRef]

39. De Temmerman, L.; Maere, T.; Temmink, H.; Zwijnenburg, A.; Nopens, I. Salt stress in a membrane bioreactor: Dynamics of sludge properties, membrane fouling and remediation through powdered activated carbon dosing. Water Res. 2014, 63, 112-124. [CrossRef]

40. Reid, E.; Liu, X.; Judd, S.J. Sludge characteristics and membrane fouling in full-scale submerged membrane bioreactors. Desalination 2008, 219, 240-249. [CrossRef]

41. Wang, Z.; Wu, Z.; Tang, S. Extracellular polymeric substances (EPS) properties and their effects on membrane fouling in a submerged membrane bioreactor. Water Res. 2009, 43, 2504-2512. [CrossRef]

42. Zhang, T.; Shao, M.F.; Ye, L. 454 pyrosequencing reveals bacterial diversity of activated sludge from 14 sewage treatment plants. ISME J. 2012, 6, 1137-1147. [CrossRef]

43. Hu, M.; Wang, X.; Wen, X.; Xia, Y. Microbial community structures in different wastewater treatment plants as revealed by 454-pyrosequencing analysis. Bioresour. Technol. 2012, 117, 72-79. [CrossRef] [PubMed]

(C) 2020 by the authors. Licensee MDPI, Basel, Switzerland. This article is an open access article distributed under the terms and conditions of the Creative Commons Attribution (CC BY) license (http://creativecommons.org/licenses/by/4.0/). 